\title{
Validation of a particle gel immunoassay for Trypanosoma cruzi antibody detection using plasma samples collected with capillary tubes
}

\author{
Marlene MY Kawai, Jose AP Salas, Luiz AP Tavares, Cor JF Fontes \\ Hospital Universitario Julio Muller, Federal University of Mato Grosso. Rua Luiz Phellipe Pereira Leite s/n, Bairro \\ Alvorada, CEP 78048-902, Cuiabá, Mato Grosso, Brazil
}

\begin{abstract}
Introduction: The Chagas disease particle gel immunoassay (PaGIA-Chagas) is a simple, fast and practical test used for the diagnosis of the chronic Chagas disease and is based on anti-Trypanosoma cruzi antibody detection in serum. This study aimed to validate the PaGIA-Chagas on plasma collected with capillary tubes.

Methodology: Serum samples from 74 T. cruzi-infected and 26 non-infected individuals were tested by conventional indirect immunofluorescence and PaGIA-Chagas. Later, plasma specimens collected with capillary tubes from these same individuals were tested by PaGIA-Chagas. Results from serum samples tested by IFA and PAGIA- Chagas were considered as the reference standard to determine the accuracy parameters of the particle gel tested on plasma samples. The inter-test agreement of T. cruzi antibody detection by PaGIA-Chagas on serum and plasma was calculated using Kappa index.

Results: The PaGIA-Chagas performed on plasma collected with capillary tubes had sensitivity and specificity of $99 \%$ and $100 \%$, respectively. The crude agreement observed with the results of the PaGIA-Chagas on plasma and serum was 99\% and the Kappa index was 0.975 (CI95\%: 0.782 - 1.000).

Conclusion: PaGIA-Chagas for anti-T. cruzi detection on plasma collected with capillary tubes is accurate and might be indicated to reduce fieldwork time and materials in epidemiological screening of chronic Chagas disease.
\end{abstract}

Key words: Chagas disease, diagnosis, particle gel immunoassay, capillary tube

J Infect Dev Ctries 2010; 4(9):590-592.

(Received 24 December 2009 - Accepted 30 April 2010)

Copyright ( 92010 Kawai et al. This is an open-access article distributed under the Creative Commons Attribution License, which permits unrestricted use, distribution, and reproduction in any medium, provided the original work is properly cited.

\section{Introduction}

Indirect immunofluorescence assay (IFA), indirect haemagglutination (IHA), and enzyme-linked immunosorbent assay (ELISA) are all routinely used in laboratories for both individual diagnosis and blood donor screening of Trypanosoma cruzi infection. The particle gel immunoassay (PaGIAChagas) is a more recent method developed to diagnose chronic Chagas disease. It uses red polymer particles sensitized with three different synthetic peptides representing antigen sequences of the parasite $(\mathrm{Ag} 2, \mathrm{TcD}$, and $\mathrm{TcE})$, as previously described by Peralta et al. [1]. In the presence of sera containing specific antibodies, these particles agglutinate and the result can be read visually through Sephadex gel (Diamed, MG, Brazil) present inside a microtube inserted in a plastic card [2].

Currently, PaGIA-Chagas is widely used to diagnose chronic Chagas disease and to screen blood donors free of anti-T. cruzi antibodies [3]. Because it is easy to use and processes samples quickly, it can be used on a large number of samples and is suitable for chronic Chagas disease screening in epidemiological surveys. This study aimed to validate the PaGIA-Chagas on plasma collected with capillary tubes to facilitate future epidemiological screening during field surveys.

\section{Methodology}

The subjects who participated in this study were recruited from the Outpatient Clinic for Infectious Diseases at Julio Muller Hospital in Cuiaba MT, Brazil, from November 2005 to September 2006. Most patients were seeking medical attention for clinical or electrocardiographic suspicion of chronic Chagas disease. Healthy blood donors and patients with confirmed hepatitis B, malaria, cutaneous leishmaniasis, collagenosis, and paracoccidiodomycosis were recruited from the same hospital to compose the sample set without $T$. cruzi infection. The study was approved by the Research Ethics Committee of the Julio Muller University 
Table 1. Results of the particle gel immunoassay performed on serum or on capillary bloodderived plasma for anti-Trypanosoma cruzi antibody detection.

\begin{tabular}{cccc}
\hline $\begin{array}{c}\text { Results from } \\
\text { plasma samples }\end{array}$ & \multicolumn{3}{c}{ Results from serum samples } \\
\cline { 2 - 4 } & Positive & Negative & Total \\
\hline Positive & 73 & 0 & 73 \\
Negative & 1 & 26 & 27 \\
Total & 74 & 26 & 100 \\
\hline $\begin{array}{l}\text { Sensitivity: } 99 \%(92 \%)-100 \%) \\
\text { Crude agreement: } 99 \%(97.1 \%-100 \%)\end{array}$ & & $\begin{array}{l}\text { Specificity: 100\% (84\% - 100\%) } \\
\text { Kappa index: 0.975(CI95\%: 0.782-1.000) }\end{array}$
\end{tabular}

Hospital. Subject participation was voluntary and the blood collection was performed only after participants had read and signed the consent form.

A blood sample was collected from each patient to obtain serum and to fill three heparinized capillary tubes (Perfecta, São Paulo, Brazil). All blood samples were tested by IFA and PaGIA-Chagas methods for serological confirmation of the presence of anti- $T$. cruzi antibodies. To avoid bias, serum samples were coded and processed along with other samples following routine laboratory procedures. The samples were considered positive for chronic Chagas disease only when both techniques revealed positive results, as previously recommended [4].

The PaGIA-Chagas takes place inside a microtube containing Sephadex gel, that is attached to a plastic card (ID-Card, Diamed, Lagoa Santa, Brazil). Briefly, $10 \mu \mathrm{l}$ of serum and $50 \mu \mathrm{l}$ of polymer (ID-Chagas Polymers, Diamed, Lagoa Santa, Brazil) were added to each microtube. The card was incubated for $5 \mathrm{~min}$ at room temperature and centrifuged for $10 \mathrm{~min}$ in a specific centrifuge (ID-Centrifuge, Diamed, Lagoa Santa, Brazil). A positive result was typically indicated by the presence of a tight red line on the top of the gel surface. A negative result was indicated by the presence of a pellet of colored particles at the bottom of the microtube following centrifugation, with no agglutinated particles present within or on top of the gel.

\section{PaGIA-Chagas on plasma collected with capillary tubes}

After collection, capillary tubes were kept in a vertical position to allow erythrocyte sedimentation and were preserved at $4^{\circ} \mathrm{C}$ for a maximum of 7 days. Before performing the test, the capillary tube was carefully cut at the lower plasma layer interface using a small diamond cutter. The plasma volume obtained was proportional to the height of the plasma column (around $15 \mathrm{~mm}$ ), which was usually enough to get the $10 \mu \mathrm{l}$ required in PaGIA-Chagas. A small rubber bulb was fitted to the capillary tube to dispense the plasma into the card microtube. The card was incubated, centrifuged, and read in the same manner as described above for serum testing.

\section{Statistical analysis}

Results from serum samples tested by IFA and PAGIA- Chagas were considered as the reference standard, to determine the accuracy parameters of the particle gel tested on plasma samples. The inter-test agreement of $T$. cruzi antibody detection by PaGIAChagas on sera and plasma was calculated using the Kappa index.

\section{Results}

The two conventional serological tests performed on serum samples from 100 recruited patients showed 74 positive and 26 negative results for $T$. cruzi infection. Antibody titres ranged from 1:40 to 1:640. Among 74 samples that were positive when the IFA and PaGIA-Chagas were performed on serum, 73 (98.6\%) were also positive when PaGIA-Chagas was performed on plasma from the capillary tubes. The single sample that disagreed in PaGIA-Chagas on serum and plasma had a low-titre antibody in IFA (1:40). All $26(100 \%)$ samples that were non-reactive for $T$. cruzi antibody in the reference tests also showed no reaction in the plasma samples from capillary tubes (Table 1). Therefore, the results of PaGIA-Chagas performed on plasma collected with capillary tubes had sensitivity of 99\% (CI95\%: 92\%-100\%) and specificity of 100\% (CI95\%: 84\%-100\%). The crude agreement and Kappa index between the two PaGIA-Chagas were 99.0\% (CI95\%: 97\% - 100\%) and 0.975 (CI95\%: $0.782-1.000)$, respectively. 


\section{Discussion}

In endemic areas, tests for diagnosis of chronic Chagas disease are not only useful to identify infected patients for subsequent treatment, but also to screen for antibody-positive individuals in surveys and in blood banks to exclude them from blood donation. For the last few years, PaGIA-Chagas has been widely used in the diagnosis of Chagas disease in blood banks and in clinical laboratories [5-7]. The main advantages of this method are its high sensitivity and speed to perform [2]. The original technique requires venous blood collection to obtain serum or plasma, which makes it less applicable in remote field studies.

Several studies have been conducted with blood collected and stored in capillary tubes, with the purpose of demonstrating the practicality of this resource in the performance of immunoassays for the diagnosis of infectious and haematological diseases [8-10]. For example, studies evaluating indirect haemagglutination in a malaria epidemiological survey showed that blood collection in capillary tubes was the most appropriate procedure for field work and did not compromise the test accuracy $[10,11]$. However, studies directed toward the diagnosis of Chagas disease using this resource were not available.

The finding of this study that there is high accuracy and an excellent correlation between the PaGIA-Chagas results obtained with serum and those obtained with capillary blood-derived plasma may facilitate field work in epidemiological studies of chronic Chagas disease. Although PaGIA may not be practicable under field conditions, since special equipment is required to perform the assay, the potential to acquire a large number of fingerstick and capillary blood samples is likely to result in overall time savings and less complex field work.

\section{References}

1. Peralta JM, Teixeira MGM, Shreffler WG, Pereira JB, Burns-Jr JM, Sleath PR, Reed S (1994) Serodiagnosis of Chagas' disease by enzyme-linked immuno-sorbent assay using two synthetic peptides as antigens. J Clin Microbiol 32: 971-974.

2. Rabello A, Luquetti AO, Moreira EF, Gadelha MF, Santos JA, Melo L, Schwind P (1999) Serodiagnosis of
Trypanosoma cruzi infection using the new particle gel immunoassay - ID-PaGIA Chagas. Mem Inst Oswaldo Cruz 94: 77-82.

3. Silveira JF, Umezawa ES, Luquetti AO (2001) Chagas disease: recombinant Trypanosoma cruzi antigens for serological diagnosis. Trend Parasitol 17: 286-291.

4. Schmunis GA (1991) Trypanosoma cruzi, the etiologic agent of Chagas disease: status in the blood supply in endemic and non-endemic countries [review]. Transfusion 31: 547557.

5. Luquetti AO, Ponce C, Ponce E, Esfandiari J, Schijman A, Rovollo S, Añezz N, Zingales B, Ramgel-Aldao R, Gonzalez A, Levin MJ, Umezawa ES, Silveira JF (2003) Chagas' disease diagnosis: a multicentric evaluation of Chagas Stat-Pak, a rapid immunochromatographic assay with recombinant proteins of Trypanosoma cruzi. Diag Microbiol Infect Dis 46: 265-271.

6. Umezawa ES, Bastos SF, Coura JR, Levin MJ, Gonzalez A, Rangel-Aldao R, Zingales B, Luquetti AO, Silveira, JF (2003) An improved serodiagnostic test for Chagas' disease employing a mixture of Trypanosoma cruzi recombinant antigens. Transfusion 43: 91-97.

7. Ponce C, Ponce E, Venelli E, Montoya A, Aguilar V, Gonzalez A, Zingales B, Rangel-Aldao R, Levin MJ, Esfandiari J, Umezawa ES, Luquetti AO, Silveira, JF (2005) Validation of a rapid and reliable test for diagnosis of Chagas' disease by detection of Trypanosoma cruzi -specific antibodies in blood of donors and patients in Central America. J Clin Microbiol 43: 5065-5068.

8. Chandler HM, Healey K, Premier RR, Hurrell JG (1984) A new rapid semi-quantitative enzyme immunoassay suitable for determining immunity to tetanus. J Infect 8: 137-144.

9. Greco VA, Byrne KM, Procter JL, Stroncek, DF (2002) Detection of antibodies in acid eluates with the gel microcolumn assay. Transfusion 42: 698-701.

10. Biswas S (2004) Inter-test comparison between filter paper absorbed blood eluate and serum for malaria serology by enzyme immunoassay: an operational feasibility. J Immunoassay Immunochem 25: 399-410.

11. Lobel HO, Nagera AJ, Chen WI, Munroe P, Mathews HM (1976) Seroepidemiologic investigations of malaria in Guyana. Am J Trop Med Hyg 79: 275-284.

\section{Corresponding author}

Cor J F Fontes

Caixa Postal 8025 Av Republica do Libano sn

Rodoviaria Parque, Cuiaba

Mato Grosso, Brazil

CEP: 78048-970

Fax: 5565 3615-8863

Email: corfontes@gmail.com.

Conflict of interests: No conflict of interests is declared. 